\title{
PROSPECÇÃO DE ÁGUAS SUBJERRANEAS NO ALTO XINGU -PARÁ - COM MÉTODOS GEOFÍSICOS ELETROMAGNÉTICOS
}

\author{
ABEL CARRASQUILLA*, MILTON J. PORSANI** \& ALLAN TAVARES***
}

\begin{abstract}
USING ELECTROMAGNETIC GEOPHYSICAL METHODS TO PROSPECT GROUND WATER IN ALTO XINGU-PARA This geophysical study was performed at Fazenda Krimet - Alto Xingu, located in the Amazon Region of Para State. We have used resistivity and electromagnetic-VLF geophysical methods to investigate the existence of underground lithological and/or structural discontinuities. The use of this methodology allowed us to indicate where are the most promissory areas for groundwater exploitation. The resistivity method permitted the definition of four geo-electrical layers: a) the first one, a dry or unsaturated layer which includes the soil; b) the second, a resistant layer probably associated with the unsaturated sediments; c) the following, a layer with saturated geological materials; and finally, d) a resistant basement. The saturated material of the third layer presents the best perpectives to act as main aquifer in the area. On the other hand, using the VLF method, we discovered several anomalies, among them, we can mention a shallow conductive zone, which reflects the existence of discontinuities in the underground materials. This is problably associated with sedimentary or fresh rocks fractures or faults related with a natural drainage channel at the surface level. This natural drainage channel and the areas where the saturated layer is thicker, are the places that present the best conditions for drilling wells and obtain groundwater resources of good quality.
\end{abstract}

Key Words: geophysical prospecting, electromagnetic methods, groundwater, Amazon region.

RESUMO Este estudo geofísico foi realizado na Fazenda Krimet no Alto Xingu, num setor da Região Amazônica localizado no Estado do Pará. Os trabalhos de campo compreenderam a utilização dos métodos eletro-resistivp e eletromagnético-VLF (Very Low Frequency), tendo como objetivo investigar a existência de descontinuidades litológicas e/ou estruturais em subsuperfície, com vistas a indicar as áreas mais promissoras à captação de águas subterrâneas. O método eletro-resistivo permitiu a definição de quatro camadas geo-elétricas: a) uma superficial, não-saturada, que inclui o solo seco; b) uma resisti vá, com sedimentos provavelmente não saturados; c) uma com material geológico saturado, logo abaixo da camada resistiva; d) substrato resistivo em profundidade. O material saturado da terceira camada é aquele que apresenta, entre as camadas descritas, as melhores perspectivas como horizonte aqüífero. Por outro lado, com o método VLF várias anomalias foram descobertas, entre elas uma região condutora rasa que reflete a existência de descontinuidades nos materiais de subsuperfície. A mesma está provavelmente associada a fraturamentos que atravessam a rocha fresca e o pacote sedimentar, possuindo correspondência em superfície com uma calha de drenagem, constituindo-se assim numa fonte de água subterrânea. Esta estrutura natural e as áreas onde a camada saturada apresenta maior espessura, se constituem nos lugares que reúnem as melhores condições para a realização de perfurações para captar águas subterrâneas.

Palavras chaves: prospecção geofísica, métodos eletromagnéticos, águas subterrâneas, Região Amazônica.

INTRODUÇÃO Em 1982, a Fundação de Amparo e Desenvolvimento da Pesquisa do Estado do Pará (FADESP) realizou uma campanha geofísica na Fazenda Krimet, a qual está localizada no município de São Félix do Xingu, no Sul do Estado do Pará (Fig, 1). O trabalho geofísico desenvolvido contou com a colaboração da empresa construtora Andrade Gutierrez S.A. e foi executado pelo Núcleo de Ciências Geofísicas e Geológicas da Universidade Federal do Pará (NCGG/UFPA), atualmente Centro de Geociências (CG/UFPA). O estudo foi realizado por intermédio dos métodos eletro-resistivo e eletromagnético - VLF, tendo como objetivo principal investigar a existência de descontinuidades litológicas e/ou estruturais de subsuperfície, com vistas a indicar as áreas mais promissoras à captação de água subterrânea. Com tal fim, foram executadas um total de 40 sondagens elétricas verticais (SEV) e três perfis eletromagnéticos com $1100 \mathrm{~m}$ de extensão. A interpretação destes dados permitiu estabelecer, dentro da área estudada, três locais com as melhores condições para a realização de perfurações, que correspondem à estrutura natural de drenagem e às áreas onde a camada saturada é mais espessa e o embasamento cristalino é mais profundo.

CONTEXTO GEOLÓgiCO A área do vale do Rio Xingu, que engloba a Bacia do Rio Fresco, encontra-se localizada na provincia geológica Tapajós, subprovincia do Xingú, nas porções sudoeste do Estado do Pará e sudeste do Estado do Amazonas (Fig. 2). Esta região ocupa grande parte das bacias hidrográficas dos rios Xingu e Tapajós, possiundo um relevo montanhoso cuja vegetação é formada por árvores de elevado porte que constituen uma mata densa conocida como Floresta Amazônica (CPRM 1972). De Almeida \& Hasui (1984) destacam as seguintes informações das unidades geológicas presentes na região e do interesse deste trabalho:

1 Seqüência sedimentar: a inferior corresponde à parte sedimentar da Formação Rio Fresco, formada de arenitos de granulação média a fina, arcósios e folhelhos, a qual preenche o sinclinório formado por rochas metassedimentares da Formação Tocandera, que é uma formação ferrífera constituída por argilitos cinza-azulados, siltitos carbonosos, antracito e arcóseos. No curso alto do Rio Fresco, os granitos ocasionaram a formação de uma grande estrutura dômica, deformando as rochas vulcânicas e os sedimentos da Formação Gorotire, constituída de conglomerados e quartzo-arenitos. Esta estrutura é capeada discordantemente por um conjunto de sedimentos elásticos finos associados a silexitos e jaspilitos, que é a seqüência sedimentar superior, conhecida como Formação Cubencranquém.

* Laboratório de Engenharia e Exploração de Petróleo, Universidade Estadual do Norte Fluminense. Rodovia Amaral Peixoto, Km 164, Imboacica. CEP:27.973-030. Macaé/RJ-Brasil. Fone/Fax:+55-247-73-6565. Internet: abel@lenep.uenf.br - http://www.lenep.uenf.br/-abel

** Programa de Pesquisa e Pós - Graduação em Geofísica. Instituto de Geociências. Universidade Federal da Bahia. Rua Caetano Moura, 123. CEP: 40210-000. Fone: 071-2370407. Federação, Salvador - Bahia - Brasil. Email: mporsani@pppg.ufba..br

*** PETROBRAS - EDISE - SEPROM. Ave. Rep. de Chile. CEP: 20132-000. Fone: 021-5343016. Rio de Janeiro - RJ - Brasil 


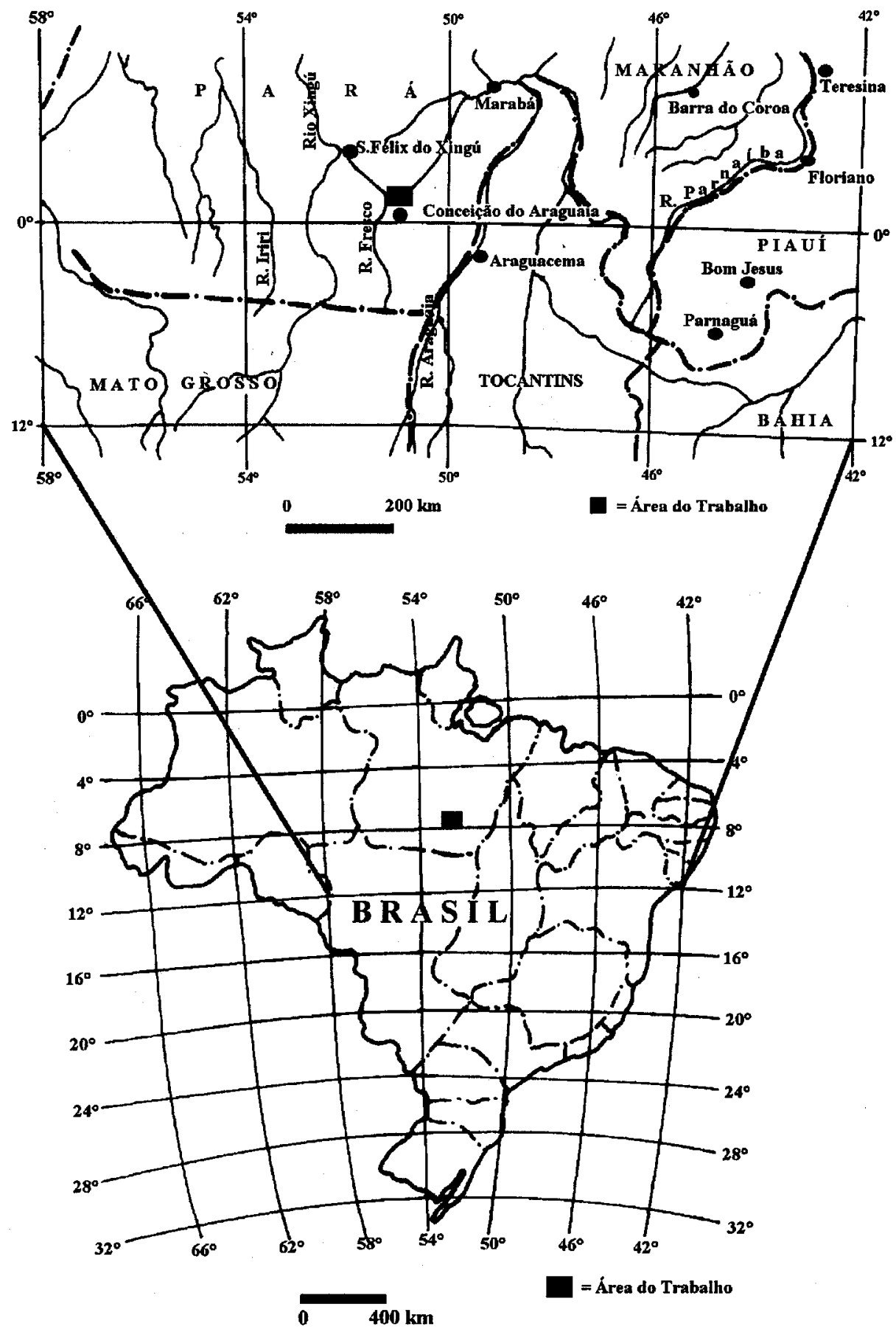

Figura 1 - Localização da área de trabalho.

Figure 1 - Localization of the studied area.

2 Rochas intrusivas/efusivas ácidas ou básicas: as relações de contato entre as rochas sedimentares com as rochas vulcânicas ainda não estão bem definidas, observando-se algumas vezes diques de andesito intrudindo os sedimentos, mas sem a presença de derrames vulcânicos. As formações presentes são conhecidas com os nomes de Sobreiro e Irirí.

3 Rochas metamórficas: as suites Jacareacanga e Cuiú-Cuiú são descritas na região. A primeira é formada por quartzitos, actinolita-xistos, mica-quartzo-xistos, quartzo-seri- cita-clorita-xistos e metapiroxenito, possivelmente associados a um provável greenstone belt. A segunda apresenta grau metamórfico mais elevado, sendo constituída por gnaisses, migmatitos, granitos, granodioritos e anfibolitos.

4 Complexo cristalino: conhecido como Complexo Xingú, é formado por rochas gnáissicas, migmatíticas e graníticas, sendo bastante restrito nessa região. Ele ocorre formando o embasamento das seqüências mais novas e aflora em poucos locais. Em seu lugar, ocorrem extensas áreas com predominância de granodioritos e granitos. 


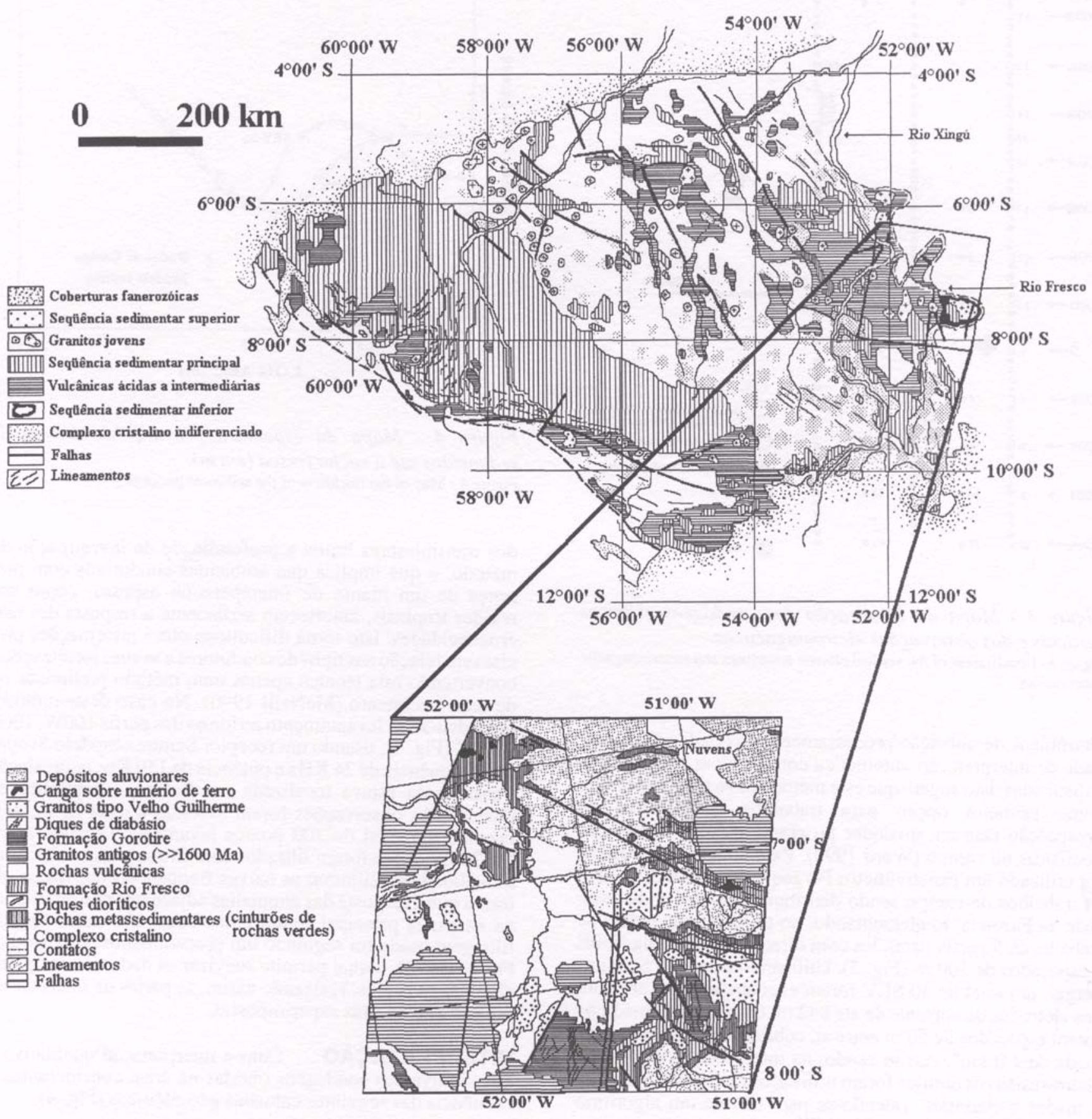

Figura 2 - Mapa geológico da região(após de Almeida \& Hasui 1984).

Figura 2 - Geological map of the region (after de Almeida \& Hasui 1984).

Quanto ao arcabouço estrutural da região, de Almeida \& Hasui (1984) mostram claramente a presença de direcionamentos no sentido NW-SE (Fig. 2). Existem fortes indicies de que fraturamentos com essa orientação controlam tanto a atividade vulcânica como a sedimentação. $\mathrm{O}$ mesmo pode ser dito com relação ao alinhamento de corpos graníticos. Assim, três direções principais de fraturamento estão presentes na região: o de direção NW é o mais importante, quando se considera a escala regional; segue-se o de direção NE com variações para NNE e ENE; e, finalmente, tem-se aquele orientado aproximadamente segundo N-S. Esta última direção é seguida pelos diques básicos intrusivos na Formação
Gorotire, no alto do Rio Fresco. Em ambos os lados do Rio Xingu, abaixo de $7^{\circ} \mathrm{S}$, as rochas sedimentares e vulcânicas das formações Rio Fresco e Gorotire apresentam-se fortemente perturbadas por masas graníticas de contornos irregulares.

Métodos Geofísicos O método eletroresistivo é usado intensamente em aplicações de problemas geotécnicos, águas subterrâneas e ambientais, devido ao seu baixo custo relativo em comparação com outros métodos, e principalmente, pelas baixas taxas de ruído, o desenvolvimento dos princípios básicos dos levantamentos de campo, os avançados sistemas 


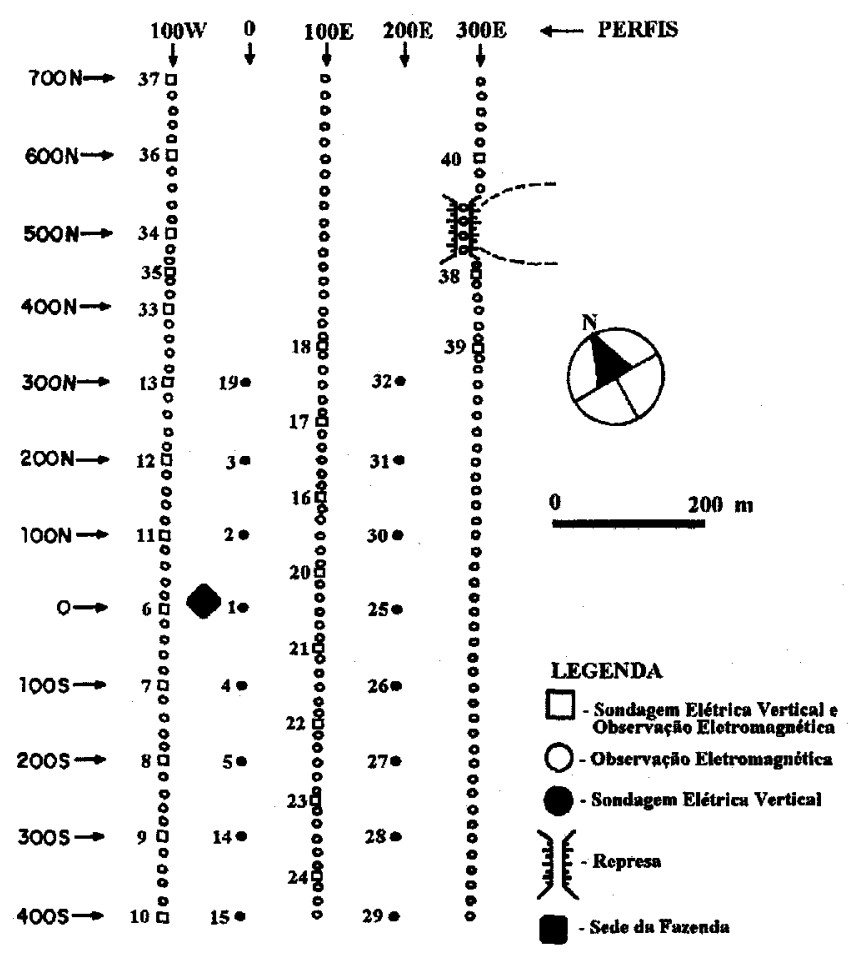

Figura 3 - Mapa da localização das sondagens elétricas verticais e das observações eletromagnéticas.

Figure 3 - Localization of the vertical electric soundings and electromagnetic observations.

eletrônicos de obtenção/processamento dos dados e a facilidade de interpretação automática com técnicas matemáticas sofisticadas. Isto sugere que este método deve ser considerado como primeira opção para trabalhos preliminares de prospecção rasa em qualquer programa de uso de técnicas geofísicas no campo (Ward 1990). Para aplicar esta técnica, foi utilizado um resistivímetro Pergeo modelo ER-300, com os trabalhos de campo sendo distribuídos ao redor da casasede da Fazenda, implementando, no terreno, uma malha de trabalho de 5 perfis paralelos com direção aproximada N30E e espaçados de $100 \mathrm{~m}$ (Fig. 3). Utilizando o arranjo Schlumberger, um total de 40 SEV foram executadas, com abertura dos eletrodos de corrente de até $842 \mathrm{~m}$. Os pontos de medição foram espaçados de $50 \mathrm{~m}$ entre si, cobrindo uma área aproximada de $1.0 \mathrm{~km}$. Assim sendo, na interpretação dos dados eletro-resistivos obtidos foram utilizados modelos teóricos de camadas horizontais, valendo-se para isto de um algoritmo desenvolvido por Rijo et al. (1977) e dos recursos computacionais pertencentes ao NCGG/UFPA. Além disso, duas sondagens características da área foram interpretadas através do processo de inversão automática com o algoritmo dos mínimos quadrados ponderados (ridge regression), com a finalidade de analizar a ambigüedade do modelo teórico utilizado (Mejú 1994).

O método eletromagnético VLF é uma técnica geofísica que utiliza fontes eletromagnéticas distantes, produzidas por potentes radio-transmissores, usadas para a comunicação com submarinos imersos. Em virtude de que o campo primário horizontal radiado propaga-se na interface ar/solo através de milhares de quilômetros, ao entrar no meio geológico pode induzir correntes nele, as quais, pela sua vez, produzem campos magnéticos que podem ser medidos com facilidade na superfície do terreno para obter informações das estruturas em sub-superfície. A alta freqüência $(15-25 \mathrm{KHz})$ e a potência

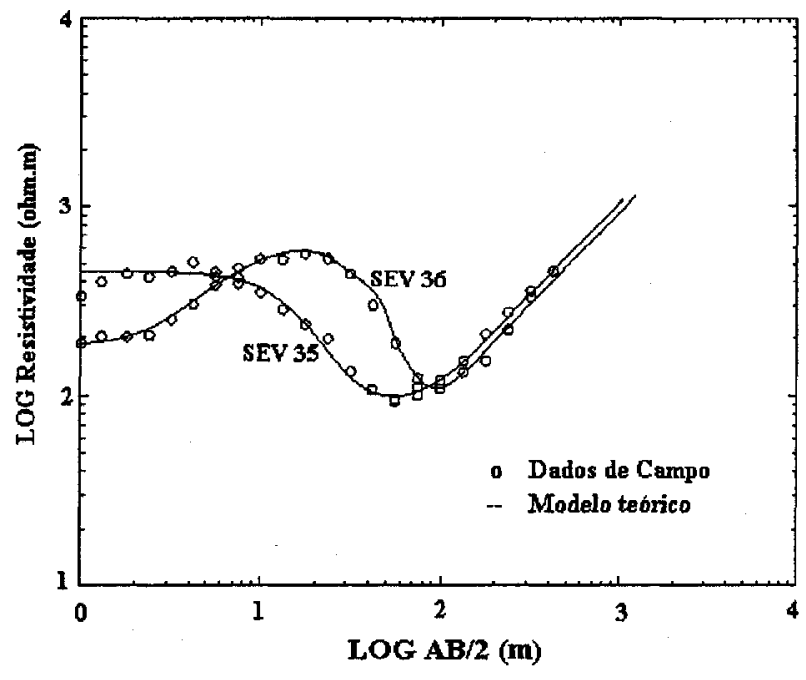

Figura 4 - Mapa da espessura provável do pacote de sedimentos até a rocha fresca (em $\mathrm{m})$.

Figure 4 - Map of the thickness of the sediment package.

dos transmissores limita a profundidade de investigação do método, o que implica que ambientes condutivos com presença de um manto de intemperismo espesso, como nas regiões tropicais, amortecem seriamente a resposta das heterogeneidades. Isto torna dificultoso obter informações precisas em relação aos tipos de condutores e as suas localizações, convertendo esta técnica apenas num método preliminar ou de reconhecimento (McNeill 1990). No caso deste método, procedeu-se ao levantamento ao longo dos perfis $100 \mathrm{~W}, 100 \mathrm{E}$ e 300E (Fig. 3), usando um receptor Scintrex modelo Scopas com freqüência de $24 \mathrm{KHz}$ e potência de $150 \mathrm{Kw}$, cuja estação transmissora estava localizada em Balboa - República de Panamá. As observações foram tomadas a cada $25 \mathrm{~m}$, perfazendo um total de 200 pontos levantados (Porsani et al 1982). Os dados foram filtrados com filtros passa - alta, com a finalidade de eliminar as baixas freqüências dos dados, de forma que a resposta das anomalias adjacentes que interferem na anomalia principal foram eliminadas. Um outro tipo de filtragem usada foi seguindo um procedimento proposto por Fraser (1970), o qual permite suavizar os dados de campo ao eliminar os ruidos, realçando assim, as partes de interesse ao separar as respostas superimpostas.

INTERPRETAÇÃO Com a interpretação qualitativa e quantitativa das sondagens obtidas na área, consideramos a existência das seguintes camadas geo-elétricas (Fig. 4):

1 Uma superficial composta de sedimentos, provavelmente da Formação Cubencranquém, a qual inclue algumas vezes um solo seco ou não-saturado, que corresponde ao trecho inicial das SEVs. Esta camada possue espessuras entre 0.5 e $12.0 \mathrm{~m}$ e resistividades muito variáveis, entre 70 e 2300 ohm.m.

2 Uma resistiva, acima do nível freático, vem a continuação. Esta camada está possivelmente relacionada com sedimentos não-saturados pertencentes à Formação Gorotire. Esta camada tem valores de resistividade entre 300 e 4300 ohm.m, e espessura variável entre 2 e $30 \mathrm{~m}$.

3 Em seguida, vem uma camada de material saturado, possivelmente abaixo do nível freático, representados por sedimentos saturados da Formação Rio Fresco ou o manto 


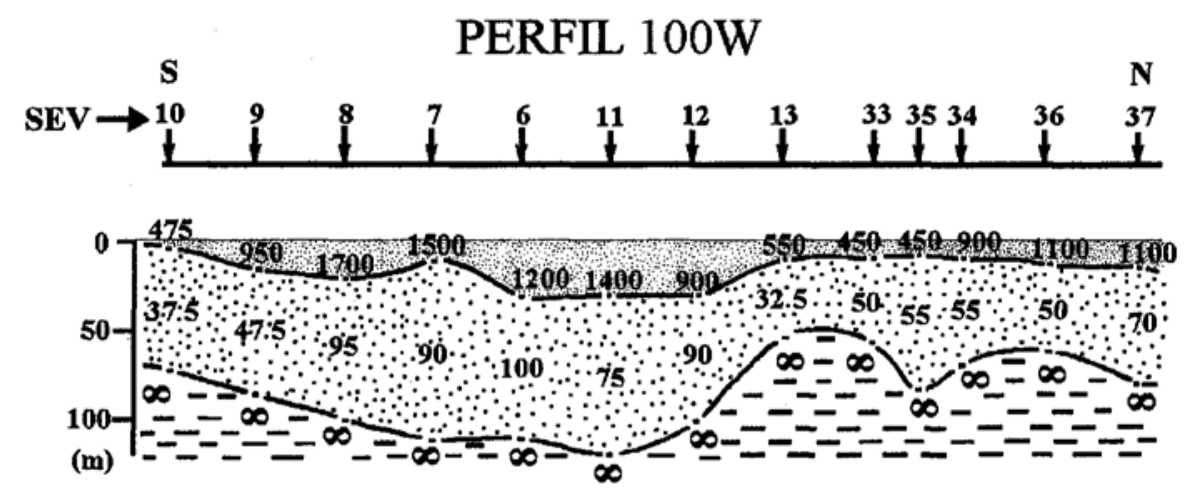

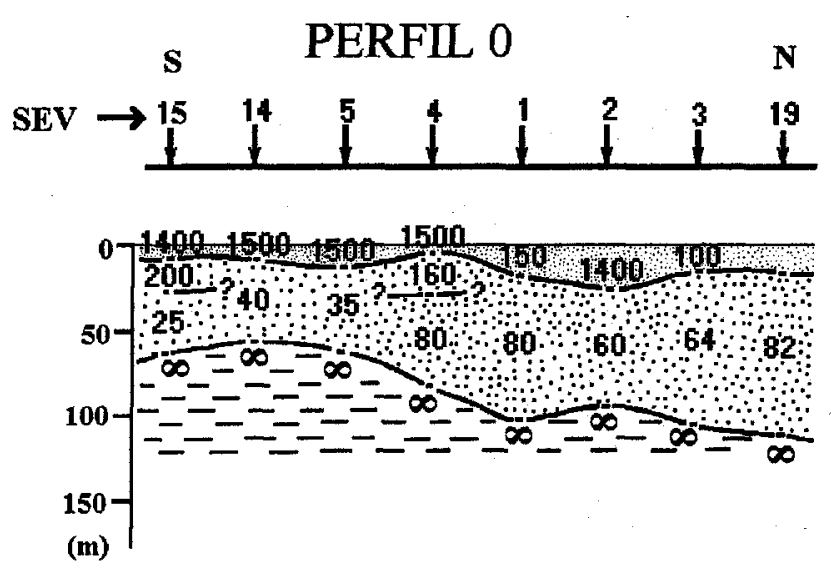

PERFIL 200E
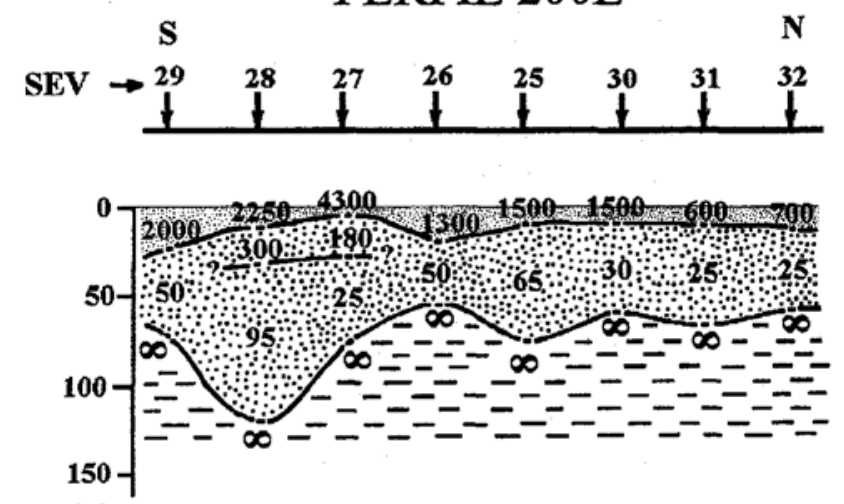

(m)

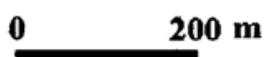

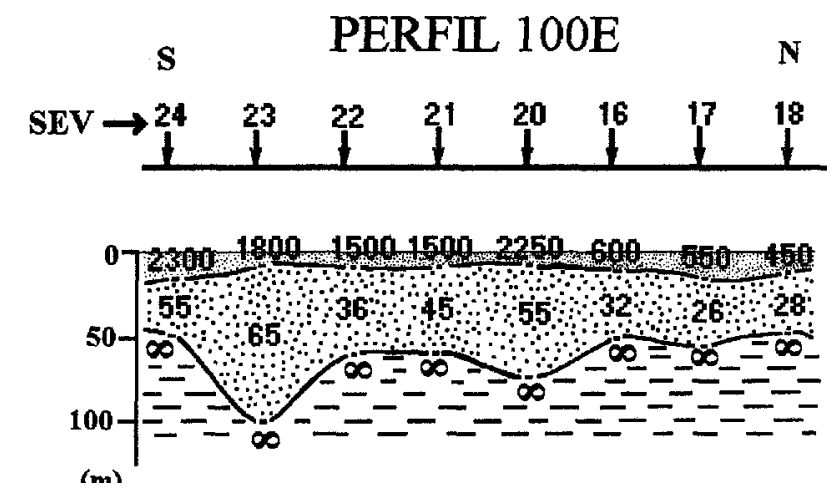

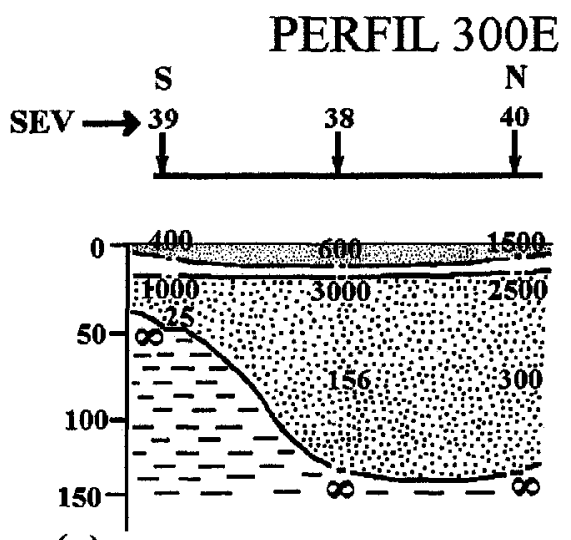

(m)

Figura 5- Seções geo-elétricas.

Figure 5 - Geo-electrical sections.

de intemperismo. Esta camada está evidenciada nos menores valores de resistividade das SEVs no seu trecho intermediário (entre 25 e $160 \mathrm{ohm} . \mathrm{m}$ ) e espessuras entre 35 e $125 \mathrm{~m}$.

4 Finalmente, apresenta-se um camada altamente resistiva pertencente ao Complexo Xingu, sobre a qual repousam as camadas antes descritas. Este substrato provavelmente corresponde a rocha fresca e está evidenciado no ramo ascendente do trecho final das curvas das SEVs, com resistividades de aproximadamente 3000 ou mais ohm.m.

Utilizando esta interpretação teórica dos dados de campo, construímos as seções geo-elétricas para os perfis $100 \mathrm{~W}, 0$,
100E, 200E e 300E (Fig. 5). Em várias dessas seções, são apresentadas juntas as duas primeiras camadas antes descritas, pois, em muitas sondagens elas aparecem como uma só. Também, é necessário observar que embora o terreno onde foi feito o levantamento se apresente levemente ondulado, para simplicidade de representação foi assumida uma topografia plana do terreno. Por outro lado, aproveitando a informação proveniente das curvas com o ramo terminal ascendente na forma de $45^{\circ}$, pelo qual inferimos a presença da rocha cristalina fresca, foi elaborado um mapa da espessura total do pacote dos sedimentos que está acima deste embasamento resistive (Fig. 6). Os locais de maior espessura deste pacote aparecem ao SW e ao NE da área estudada. 


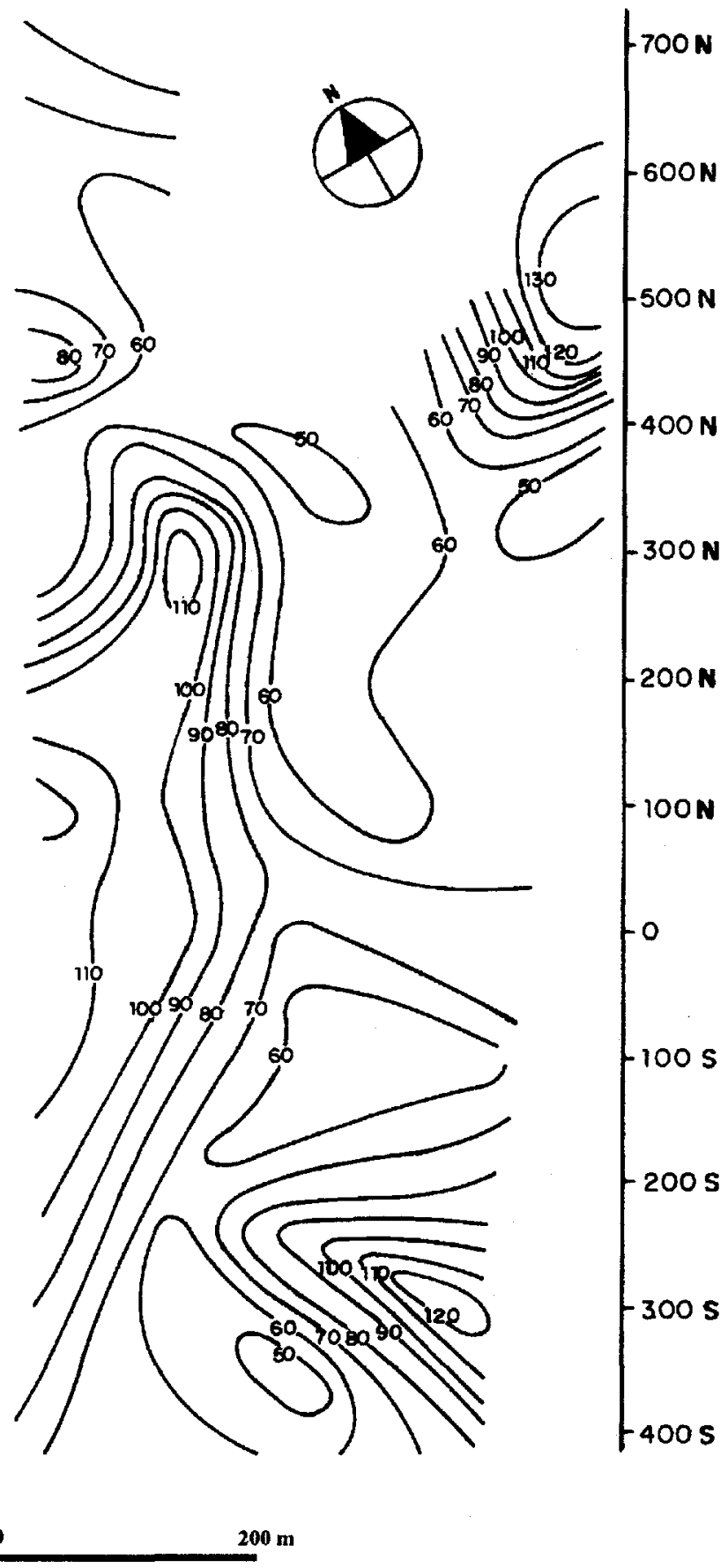

Figura 6 - Sondagens elétricas verticais características da área (SEVs 35 e 36).

Figure 6 - Typical vertical electric soundings of the area (VES 35 and 36).

No ajuste automático dos dados de campo e o modelo teórico estratificado no processo de inversão das SEVs 35 e 36, foi alcançado um mínimo com três iterações nos dois casos, dando los resultados mostrados na Tabela 1 , em que $p$ representa resistividade em ohm.m e h, a espessura de cada camada em $\mathrm{m}$. A pesar do bom ajuste matemático do modelo aos dados de campo, expressado com baixos erros de ajuste de 0.24 e $0.39 \%$ para as SEVs 35 e 36, respectivamente, os altos desvios padrões dos parâmetros (especificamente no caso da resistividade da última camada) mostram que esses
Tabela 1 - Modelos iniciais e finais das SEVS 35 e 36 Table 1 - Initial and final models of the SEV's 35 and 36

\begin{tabular}{|l|r|r|c|c|}
\cline { 2 - 5 } \multicolumn{1}{c|}{} & \multicolumn{2}{c|}{ Modelo Inicial } & \multicolumn{2}{c|}{ Modelo Final \pm Desvio } \\
\cline { 2 - 5 } \multicolumn{1}{c|}{} & $\rho$ (ohm.m) & $\mathrm{h}(\mathrm{m})$ & $\rho$ (ohm.m) & $\mathrm{h}(\mathrm{m})$ \\
\hline SEV 35 & 350.0 & 1.0 & $313.0 \pm 13.5$ & $0.4 \pm 53.0$ \\
& 500.0 & 8.0 & $453.4 \pm 3.2$ & $8.0 \pm 5.0$ \\
& 85.0 & 70.0 & $81.4 \pm 3.8$ & $69.0 \pm 6.5$ \\
& 1500.0 & & $1559.5 \pm 202.4$ & \\
\hline SEV 36 & 180.0 & 1.9 & $185.8 \pm 5.7$ & $2.2 \pm 10.7$ \\
& 3000.0 & 10.0 & $1564.3 \pm 29.8$ & $6.6 \pm 30.5$ \\
& 50.0 & 50.0 & $59.0 \pm 24.2$ & $67.9 \pm 29.0$ \\
& 2000.0 & & $2811.8 \pm 37639.6$ & \\
\hline
\end{tabular}

dados possuem informações que não pertencem propriamente a este tipo modelo. Isto sugere a existência de heterogeneidades bi ou tridimensionais em subsuperfície do tipo intrusões magmáticas, fraturas ou ainda variações laterais nas camadas aflorantes que provocam perturbações nas sondagens.

A figura 7 apresenta os perfis eletromagnéticos das observações de campo conjuntamente com as observações filtradas. A interpretação conjunta desses perfis permite verificar a existência de uma região condutora disposta segundo a direção aproximada N60W. A profundidade em que está localizada esta heterogeneidade não pode ser conhecida com certeza apartir destes dados, mas deve estar acima dos $60 \mathrm{~m}$, que é a penetração usual do método VLF em terrenos condutivos do tipo encontrado na Amazônia. Na figura 8 são apresentados os mapas de contorno dos dados VLF antes e depois da filtragem. Nestes mapas, as partes mais claras representam as estruturas anômalas, as quais ficam mais evidentes após a filtragem Fraser. A anomalia da direita é aquela relacionada com a calha natural de drenagem, sobre a qual está situada a represa que abastece a fazenda e que tem continuidade do outro lado do Rio Fresco. Existe correspondência, quanto à direção, entre esta estrutura e a família de fraturas descritas por de Almeida \& Hasui (1984), sendo a mesma a que apresenta maior interesse em relação à localização de poços para aproveitamento de recursos hídricos subterrâneos. As outras anomalias presentes nos gráficos, no centro da figura, podem estar relacionadas com estruturas em subsuperfície, que correspondem à intrusões magmáticas descritas na geologia como pertencentes às formações Sobreiro e Irirí com as mesmas direções NW-SE, ou com ruido introduzido nos dados, causado pela influência da topografia, pelas correntes telúricas ou pela atividade cultural, este último provavelmente causado pelas linhas de corrente elétrica presentes na Fazenda.

CONCLUSÕES A análise conjunta dos resultados geofísicos obtidos pelos dois métodos permite indicar o trecho compreendido entre as SEV 38 e 40, como aquele que reúne, dentro da área pesquisada, as melhores condições para realização de perfurações que forneçam água subterrânea para a Fazenda. Estas SEVs, realizadas respectivamente nas posições $450 \mathrm{~N}$ e $600 \mathrm{~N}$ no perfil $300 \mathrm{E}$ e situadas na encosta da serra ao lado esquerdo e direito da represa, indicam que a rocha fresca encontra-se, naquele local, a uma profundidade de cerca de 130 metros e a camada saturada apresenta neste local a sua maior espessura (aproximadamente $100 \mathrm{~m}$ ). Uma outra opção, de menor importância, é a área que compreende as SEV 23 e 28, conforme se observa nas seções geo-elétricas dos perfis $100 \mathrm{E}$ e $200 \mathrm{E}$, bem como no mapa de contorno da espessura do pacote de sedimentos. Essa região também corresponde a uma depressão no topo da rocha fresca, porém, sem apresentar evidencias nos perfís eletromagnéticos. A região condutora presente nos perfis eletromagnéticos, por outro lado, reflete a existência de descontinuidades nos materiais de 

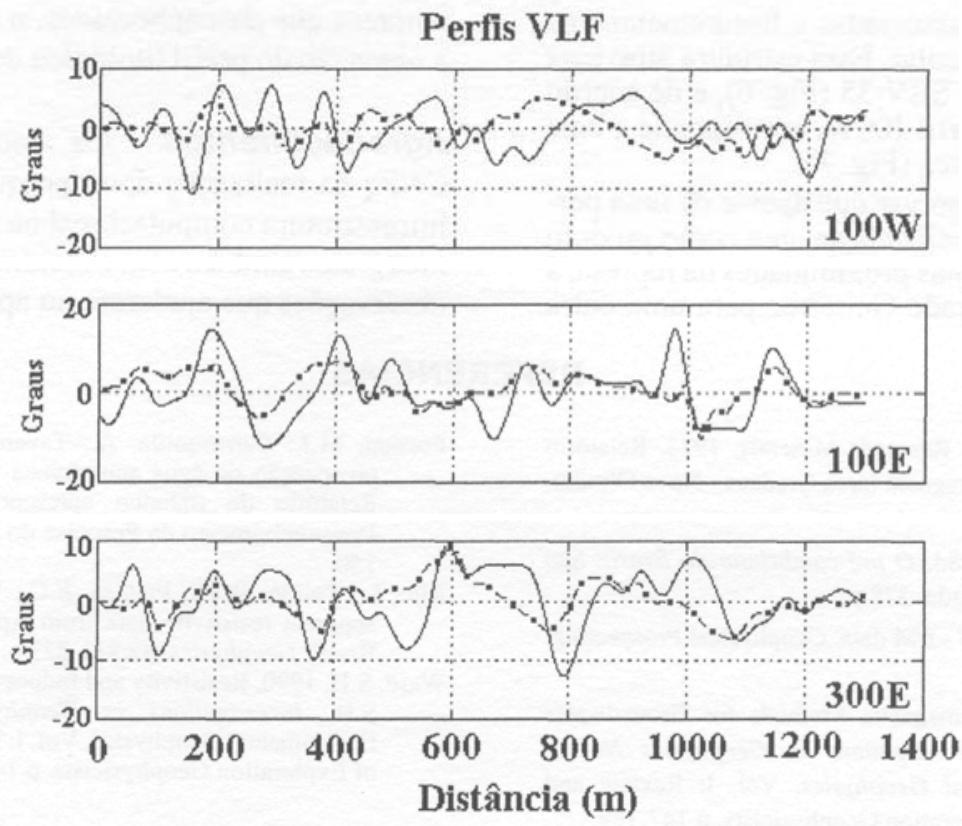

-.- Dados sem Filtrar

— Dados Filtrados

Figura 7 - Perfis da observações eletromagnéticas sem filtro (tracejada) e com filtro (sólida). Figure 7 - Electromagnetic observations profiles: without a filter (dashed line) and with a filter (solid line).

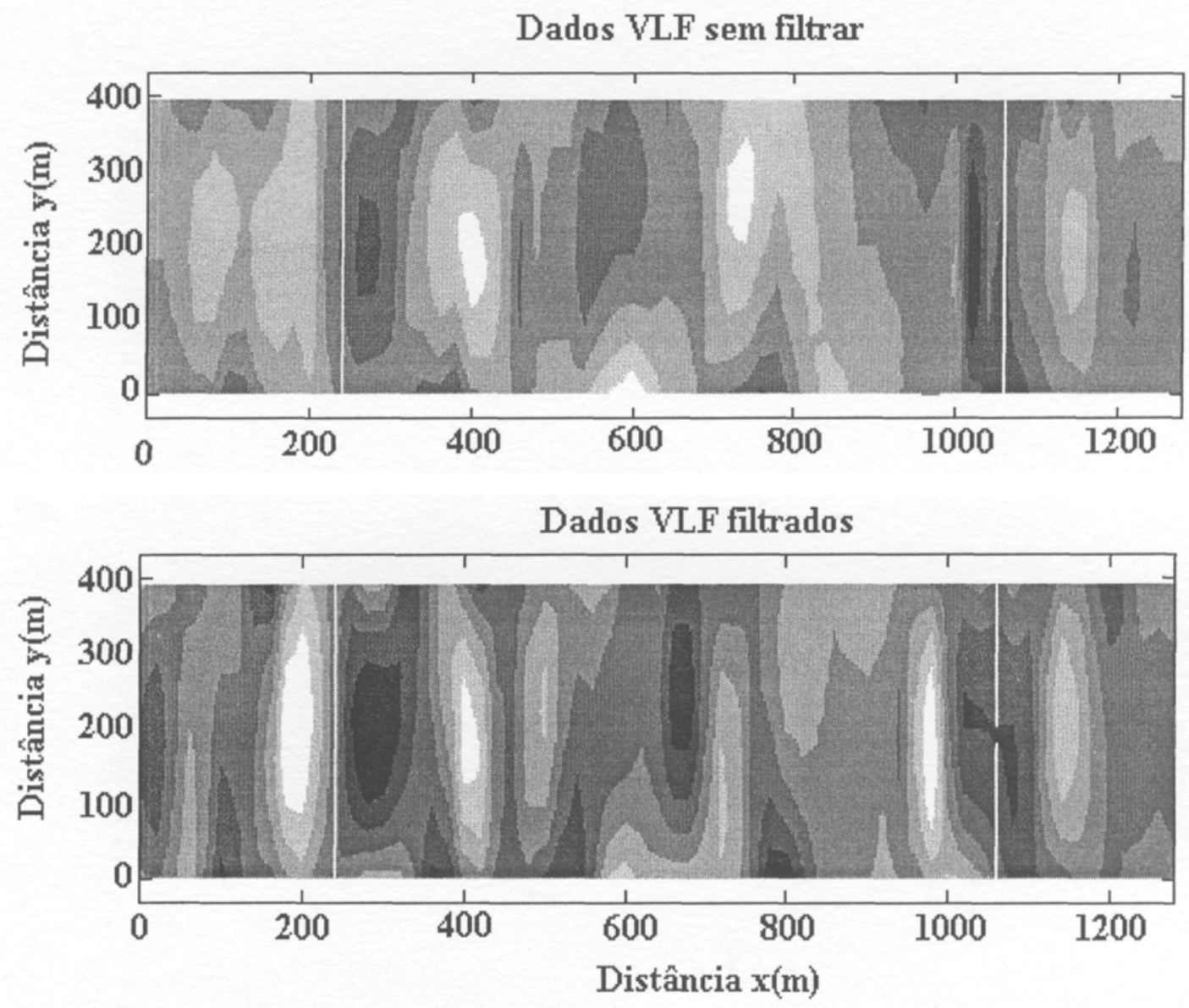

Figura 8 - Mapas de contorno das observações eletromagnéticas sem filtro (no alto) e com filtro (embaixo). Figure 8 - Electromagnetic observations contour maps: without a filter (top) and with a filter (bottom). 
subsuperfície, provavelmente associadas a fraturamentos na rocha fresca e no pacote sedimentar. Essa estrutura atravessa o ponto em que foi realizada a SEV 35 (Fig. 6), e de acordo com a seção geo-elétrica do perfil $100 \mathrm{~W}$, corresponde a uma depressão no topo da rocha fresca (Fig. 7).

Finalmente, é necessário observar que apesar de uma perfuração com sucesso ter sido realizada na área como produto da recomendação deste estudo nas proximidades da represa, a fazenda foi vendida pela Andrade Gutierrez para uma outra empresa que desconhecemos, o que dificultou sobremaneira a obtenção do perfil litológico do poço construído.

Agradecimentos Os autores agradecem o apoio do $\mathrm{CNPq}$ na realização desta pesquisa, ao LENEP/UENF pela infraestrutura computacional na fase final da elaboração. Somos gratos também com os senhores revisores, pelas acertadas observações que ajudaram no aprimoramento deste artigo.

\section{REFERÊNCIAS}

CPRM - Companhia de Pesquisa de Recursos Minerais. 1972. Relatório Geológico do Projeto Xingu -Araguaia (área Gradaus - Nova Olinda), Vol. 1,147 p. aaa

De Almeida, F.F.M. \& Hasui, Y. 1984. O pré-cambriano do Brasil. São Paulo, Editora Edgrad Bücher Ltda. 378 p.

Fraser, D.C. 1970. Contouring of VLF - EM data. Geophysical Prospecting, 34:958-967.

McNeill, J.D. 1990. Use of Electromagnetic Methods for Groundwater Studies. In: WARD, S.H. Investigations in Geophysics No. 5, Geotechnical and Enviromental Geophysics, Vol. I: Review and Tutorial. Tulsa, Society of Exploration Geophysicists. p.147-189.

Meju, M. 1994. Geophysical data analysis: understanding inverse problem theory and practice. Society of Exploration Geophysicists, Tulsa. 296 P.
Porsani, M.J.; Carrasquilla, A.; Tavares, A. 1982. Geofísica aplicada à prospecção de água subterrânea na fazenda Krimet - Sul do Pará Relatório do trabalho apresentado à Fundação de Amparo e Desenvolvimento da Pesquisa do Estado do Pará (FADESP), Belém, 150 .

Rijo, L.; Pelton, W.H.; Feitosa, E.G.; Ward, S.H. 1977. Interpretation of apparent resistivity data from Apodi Valley, Rio Grande do Norte, Brasil. Geophysics, 42:811-822.

Ward, S.H. 1990. Resistivity and Induced Polarization Methods. In: WARD, S.H. Investigations in Geophysics No. 5, Geotechnical and Enviromental Geophysics, Vol. I: Review and Tutorial. Tulsa, Society of Exploration Geophysicists. p 147-189.

MANUSCRITO A836

Recebido em 15 de novembro de 1994

Revisão dos autores em 05 de outubro de 1997 Revisão aceita em 08 de outubro de 1997 